\title{
Functional dyspepsia: new insights into pathogenesis and therapy
}

Nicholas J. Talley

Department of Gastroenterology, John Hunter Hospital, The University of Newcastle Australia Faculty of Health and Medicine, Newcastle, Australia

Received: February 14, 2016

Accepted: March 5, 2016

\section{Correspondence to}

Nicholas J. Talley, M.D.

Department of Gastroenterology, The University of Newcastle Australia Faculty of Health and Medicine, HMRI Building Lot 1 Kookaburra Circuit, University Drive, Callaghan 2308, Australia Tel: +61-2-49215855

Fax: +61-2-40420034

E-mail: Nicholas.talley@newcastle.edu.au
One in 10 people suffer from functional dyspepsia (FD), a clinical syndrome comprising chronic bothersome early satiety, or postprandial fullness, or epigastric pain or burning. Postprandial distress syndrome (PDS, comprising early satiety and/or postprandial fullness) and epigastric pain syndrome (EPS) are increasingly accepted as valid clinical entities, based on new insights into the pathophysiology and the results of clinical trials. Diagnosis is based on the clinical history, and exclusion of peptic ulcer and cancer by endoscopy. Evidence is accumulating FD and gastroesophageal reflux disease are part of the same disease spectrum in a major subset. The causes of FD remain to be established, but accumulating data suggest infections and possibly food may play an important role in subsets. FD does not equate with no pathology; duodenal eosinophilia is now an accepted association, and Helicobacter pylori infection is considered to be causally linked to dyspepsia although only a minority will respond to eradication. In those with EPS, acid suppression therapy is a first line therapy; consider a $\mathrm{H}_{2}$ blocker even if proton pump inhibitor fails. In PDS, a prokinetic is preferred. Second line therapy includes administration of a tricyclic antidepressant in low doses, or mirtazapine, but not a selective serotonin reuptake inhibitor.

Keywords: Duodenum; Eosinophils; Helicobacter pylori; Acids; Prokinetic

\section{INTRODUCTION}

Excessive fullness after eating or the inability to finish a normal sized meal and recurrent epigastric pain are common symptoms and reasons for consulting a medical professional [1]. Structural investigations, including esophagogastroduodenoscopy (EGD), usually fail to identify an obvious organic explanation, and these patients are labeled as having functional dyspepsia (FD). Other terms applied to the same condition in the past have included nervous dyspepsia, non-ulcer dyspepsia (NUD) and essential dyspepsia, but FD is now the most common diagnosis and is included in the Rome criteria classification of functional gastrointestinal dis- orders (FGIDs). FD is important because it is not only highly prevalent but also impairs quality of life, work performance and family relationships and incurs a high healthcare cost worldwide [2].

Over the past decade, there has been a dramatic change in how FD has been conceptualized, from a brain-gut motility disorder, in which the gut pathology is absent, to a gut driven disorder with observable gastrointestinal pathology [3]. Randomized controlled trials have confirmed that infection can cause FD, most notably Helicobacter pylori [4]. Post-infectious FD following bacterial gastroenteritis has also been recognized and may have a distinct pathophysiology, while the role of the microbiome has yet to be established but is likely to be 
important [5]. Emerging data suggest that up to $40 \%$ of patients with FD have a duodenal pathology, including an increase in eosinophils that may account for the symptoms $[6,7]$. Other data suggest that the systemic and psychological symptoms often experienced by patients with FD may, in some, be explained by cytokine release from an inflammatory focus [8]. In this review the epidemiology, pathophysiology and treatment of FD are summarized, with a particular focus on data published over the last decade.

\section{DEFINITIONS}

The Rome III criteria recommend defining FD based on the presence of one of more of four cardinal gastroduodenal symptoms, namely epigastric pain, epigastric burning, postprandial fullness, and early satiety (inability to finish a normal sized meal) [9]. The symptoms of FD present over the preceding 3 months and are chronic (of at least 6 months duration). Epigastric pain or burning are typical ulcer-like symptoms and fit closely with what was previously known as NUD. The Rome III criteria labels those with epigastric pain and/or burning as epigastric pain syndrome (EPS). Burning in the epigastrium should be distinguished from retrosternal burning (heartburn), although FD and gastroesophageal reflux disease (GERD) do overlap, as discussed below. Postprandial fullness and an inability to finish a normal sized meal (early satiety) are suggestive of gastroduodenal dysmotility; patients with one or both of these symptoms are classified by the Rome III criteria as postprandial distress syndrome (PDS).

While the Rome criteria do not consider bloating as a gastroduodenal symptom, the Asian Consensus Report on FD suggested including upper abdominal bloating, as it is a common feature in patients from the region [4]. However, many patients find it difficult, if not impossible, to locate their bloating in the upper abdomen, and bloating may arise from lower down in the gut [10]. Nausea is another common symptom that can occur in FD but also is common in other FGIDs and appears not to be a specific feature [11].

The Rome criteria for FD have been the subject of considerable criticism. The major objection is that they do not discriminate FD from peptic ulcers or other organic diseases known to cause dyspepsia, and this applies to all versions published to date [12]. The failure of the criteria to provide a positive diagnosis is far from surprising and likely reflects the limited repertoire of the body to respond to injury or pathophysiological disturbances. Nevertheless, there have been major advances over the last decade in the identification of PDS and EPS cases, as well as new findings on the pathogenesis of FD, as discussed below.

\section{EPIDEMIOLOGY}

Epidemiological studies have confirmed that EPS and PDS are distinct syndromes. A pivotal population-based study (the Kalixanda study, named after the towns of Kalix and Haparanda where the research was conducted) obtained a random sample from two northern Swedish towns where subjects were invited to complete validated questionnaires and undergo an unsedated EGD to exclude esophagitis, peptic ulcer, and cancer [13]. Of 1,000 representative community subjects from Kalix and Haparanda who underwent EGD, $4 \%$ had organic disease that explained their dyspepsia, while $16 \%$ had FD, of whom $5 \%$ had EPS and 12\% PDS [14]. Other population-based studies from Europe and the United States have confirmed that PDS is more prevalent than EPS [15].

In Asia, epidemiological studies have also identified FD as a highly prevalent disorder $[16,17]$. In a Korean telephone survey of 5,000 subjects who completed the Rome III questionnaire, 7.7\% had dyspepsia; postprandial distress was reported by $5.6 \%$ and EPS by $4.2 \%$, while $27 \%$ had both PDS and EPS [18]. Other data from Asia and the West suggest that the overlap of PDS and EPS is much lower among those patients who consult their medical practitioners [3]. However, in outpatients presenting with FD, the overlap of PDS and EPS is more pronounced, and some patients are difficult to place into subgroups [19].

Risk factors for PDS and EPS remain to be fully characterized. In the Swedish population-based study, anxiety and nonsteroidal anti-inflammatory drugs (NSAIDs) were linked to PDS but not EPS [14]. Depression was not identified as an important risk factor for either subgroup. In an Italian population-based endoscopy study, smoking was linked to PDS but not EPS [15]. In contrast, 
in a large gastric cancer screening population from Taiwan, anxiety and NSAIDs were risk factors for both PDS and EPS, while $H$. pylori and depression were linked to PDS [20]. These data are in contrast with clinical trial data from Asia, which suggested that $H$. pylori responders were more likely to have EPS than PDS, but this finding requires confirmation [21]. If risk factors do differ between Eastern and Western populations, an explanation needs to be identified, as this may provide new hints regarding the pathogenesis. For example, dietary differences may impact the intestinal microbiome, and this may in turn modulate any inflammatory process that leads to FD. Little is known about the microbiome in FD [22].

Other intriguing associations remain to be confirmed. For example, an increased prevalence of joint hypermobility syndrome has been observed in FD, but rates were also surprisingly high in the controls [23]. A link to autoimmune disease is possible but needs to be verified [24].

The drivers leading people to seek consultation for FD are poorly defined. In a community study from Hong Kong, anxiety was identified as an independent risk factor for seeking health care [25], but other studies have not confirmed these observations $[26,27]$. The severity of the dyspepsia also drives people to seek care, although over $50 \%$ of affected individuals do not seek consultation [28] despite many believing they have a serious condition [29].

\section{PATHOPHYSIOLOGY}

The causes of FD remain to be established, but accumulating data suggest infections and possibly food may play an important role in a subset of individuals, as reviewed below (Fig. 1).

\section{Meals induce symptoms in the majority of individuals}

Food ingestion plays an important role in the genesis of FD symptoms, although the mechanisms remain to be elucidated. In a previous study, a standard solid meal was given to 218 tertiary care patients with FD, and symptom severity was measured every 15 minutes for 4 hours [30]. Even if patients failed to recognize a relationship between eating and their symptoms, nearly $80 \%$ had increased symptom intensity 15 minutes after the meal. Notably, the timing varied by symptom type, with fullness occurring much earlier than pain after the meal. Interestingly, those patients with EPS were also more likely to report a delayed peak in pain, suggesting they frequently have true meal-induced symptomatology, but it often goes unrecognized [30].

High-fat meals slow gastric emptying and can lead to dyspepsia, while moderate-to-fast eating and irregular meals are also associated with dyspepsia [31,32]. The role of disturbances in gut hormones in FD postprandially is uncertain, although increased cholecystokinin and ghrelin have both been implicated potentially [33,34].

\section{Gastric perturbations}

Traditionally, FD has been conceptualized as a motility disorder dominated by disturbances in gastric physiology. There are conclusive data suggesting that gastric emptying is delayed in a subset of people with FD, although the prevalence varies widely (from 10\% to $40 \%$, with a median of 25\%) [3]. Occasionally, gastric emptying is fast rather than slow in FD, although most have normal emptying. Notably, symptoms correlate very poorly with slow gastric emptying in FD, suggesting the finding is likely an epiphenomenon $[3,8,9]$.

Normally after a meal, the gastric fundus relaxes, allowing a pleasant feeling of satiation, and this is lost af-

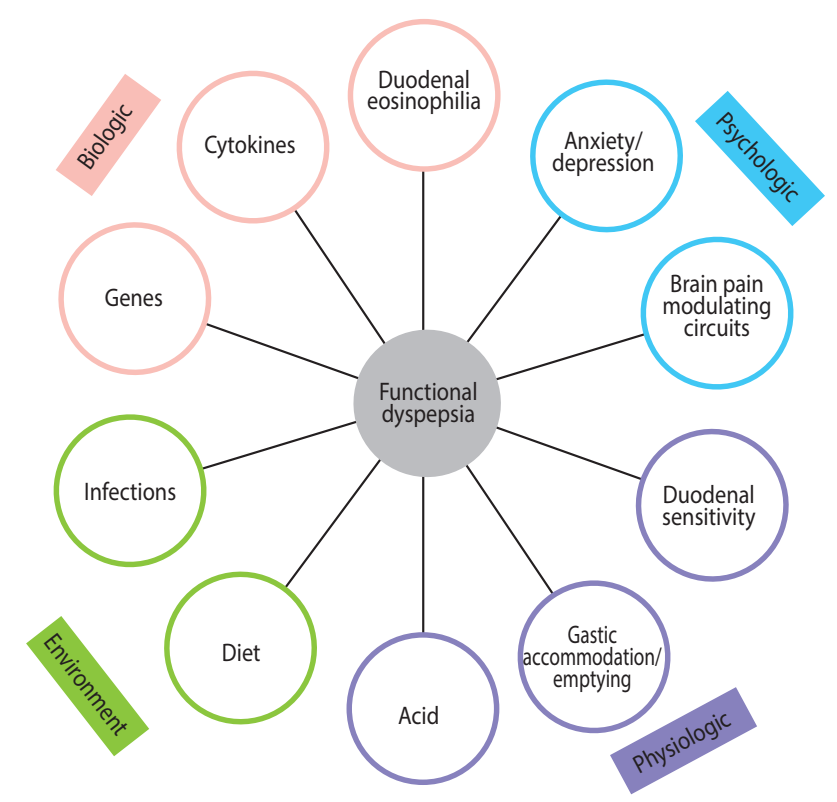

Figure 1. Mechanisms contributing to functional dyspepsia. 
ter vagotomy [3]. Relaxation of the gastric fundus is also impaired in a subset of people with FD, affecting up to $40 \%$ of cases (termed fundic disaccommodation), and this has been linked to early satiety in some but not all studies [3]. In a subgroup of FD, the stomach also exhibits hypersensitivity, as shown by distending a barostat balloon in the stomach; patients with FD feel the balloon at lower volumes and pressures than do controls, but the link to symptoms is tenuous [3,35]. Disturbed gastric physiology may alter food intake in FD; a lower body mass index has been observed in a subset of FD patients in some studies [36,37], and obesity is uncommon in this syndrome.

\section{Duodenal perturbations}

More recent research has focused on the duodenum, where disturbed motor and sensory functions have also been observed in patients with FD. Acid infusion into the duodenum can induce symptoms and motility changes in FD [38]. This was unexplained in adults, until observations of a subtle increase in eosinophils in the duodenum in FD were reported [39]. Talley et al. [39] hypothesized a priori that eosinophils are recruited to the duodenum secondary to duodenal acid or food allergen exposure in FD, and then degranulate, releasing toxic products, such as major basic protein, to signal local mucosal pain fibers. In the Kalixanda study, a quantitative increase in duodenal eosinophils was observed in cases with FD compared with the controls, with increased clusters of eosinophils in FD and degranulation adjacent to nerves in some cases. Counting of eosinophils is key, as eosinophilia is subtle, and the association would otherwise have been missed (as it has been in adults until recently) [39]. These initial observations have been confirmed in Western and Eastern populations [6,40-42], and research from Belgium has reported that increases in eosinophils are associated with increased mucosal permeability [43]. Further research has suggested that duodenal eosinophilia is linked to pain and early satiety, and the risk is increased in smokers [6]. A large-scale epidemiological investigation also associated FD with atopic conditions [44].

Perturbations in the duodenum may theoretically induce reflex responses that alter gastric physiology, possibly explaining the altered gastric emptying and other findings in FD [38]. Other research has shown that delayed gastric emptying in FD is linked to circulating small bowel homing T cells $\left(\mathrm{CD}_{4}+\alpha_{4} \beta_{7}+\mathrm{CCR}_{9}+\right.$ lymphocytes) as well as cytokine release (tumor necrosis factor $\alpha$ [TNF- $\alpha$ ], interleukin $1 \beta[\mathrm{IL}-1 \beta]$, and IL-10 secretion), supporting the view that small intestinal inflammation may be a primary driver of gastric dysfunction [8].

\section{Infections}

Post-infectious FD is a newly-recognized syndrome and can follow infection by several organisms, including, Salmonella, Escherichia coli, Campylobacter, giardiasis or norovirus, and possibly other upper intestinal infections as well [5]. Follow-up of cases after acute bacterial gastroenteritis has shown that those exposed to these infections have an approximately 2.5-fold increased risk of developing FD, and an increased risk of developing both FD and irritable bowel syndrome (IBS) [5]. Those who have a more severe infection or who smoke are at increased risk. Other data have shown that smokers have an increased risk of duodenal eosinophilia, which is also linked to FD [6].

It had been debated whether H. pylori is a cause of FD, but the evidence is now clear. While in the majority of cases of $\mathrm{H}$. pylori, the associated histological gastritis appears to have no clinical effect, in an important minority, curing the infection leads to long-term symptom resolution even a year after completing eradication therapy [45]. A meta-analysis of randomized controlled trials concluded that $H$. pylori eradication is superior to the placebo (or short-term acid suppression), with a number needed to treat (NNT) of 17 [46]. The role of the microbiome in the pathogenesis of FD is otherwise largely unknown but may be altered by dietary changes or possibly inflammation [22].

\section{Brain-gut disturbances}

Psychological distress is associated with FD, with a strong link to anxiety $[14,47]$. The best evidence for the role of anxiety comes from longitudinal investigations of subjects free of FD symptoms. In the Kalixanda study, the development of FD was nearly 8-fold higher in those with baseline anxiety, suggesting a cause and effect relationship [48]. Early life factors are likely key, with the possibility of a vicious cycle developing in which mood disturbance exacerbates dyspepsia, which in turn in- 
creases the severity of the mood disorder [47].

In many cases, anxiety may precede the disorder (a brain-gut link), but in others, the gut symptoms may precede the anxiety (suggesting a gut-brain link) [48]. How might the gut alter brain-inducing anxiety? Symptoms may increase anxiety; alternatively, another potential mechanism is through cytokine release secondary to gut inflammation. For example, TNF- $\alpha$ was significantly increased and correlated with greater anxiety in IBS [49], while cytokine release has been linked to slow gastric emptying in FD [8].

Imaging studies have identified changes in the relevant brain regions where pain-modulating circuits exist, compared with the controls [50]. Assessing resting brain glucose metabolism by fluorodeoxyglucose positron emission tomography (PET) revealed higher metabolism levels in a number of brain regions considered to be part of the key pain modulatory circuits, including the anterior cingulate cortex, insula and thalamus. These changes correlated with symptom severity but not anxiety [51], although other studies have suggested that patients with anxiety or depression and FD demonstrate greater hypermetabolism in these circuits [52]. Structural changes in gray matter density have also been reported in PDS [53]. A limiting aspect of that research was the lack of controls with chronic non-gut pain to ascertain if the changes seen were disease-specific or reflected non-specific alterations with chronic pain. The central neurotransmitter systems involved in FD remain to be defined fully, but recent preliminary PET data have identified a higher presence of cerebral cannabinoid-1 receptors in FD, implicating sustained endocannabinoid system dysfunction, which may represent a new central therapeutic target [54].

\section{Genetics}

Limited data have implicated genetic factors in FD [55]. GNbeta3, which alters G-protein activation and multiple other pathways, was the first single nucleotide polymorphism (SNP) associated with FD [56], and a number of studies have confirmed a link, although the associations vary by population [55]. The nitric oxide synthase (NOS) gene (namely the T-allele of neuronal NOS) has also been linked to FD [57]. Other SNPs possibly linked to FD include those in TRPV1, which is related to acid sensitivity [58], and the tetrodotoxin-resistant sodium chan- nel $\mathrm{Na}(\mathrm{V})$ 1.8, which is involved in nociception $[58,59]$. In post-infectious FD, Japanese investigators have linked a cyclooxygenase 1 polymorphism to EPS, but this remains to be confirmed [59,60]. Small sample numbers and inadequate validation remain issues for most of these associations [61].

\section{A disease model for FD}

It has been hypothesized that either a food allergen or infection in a genetically predisposed host can induce upper small intestinal permeability, leading to antigen presentation and immune activation, with a switch from a $\mathrm{TH}_{1}$ to a $\mathrm{TH} 2$ response [62-64]. This in turn leads to recruitment of eosinophils that degranulate, resulting in some, but not all, cases of FD developing focal tissue injury and producing cytokines and circulating homing $\mathrm{T}$ cells that induce gastric perturbations and satiety. Eosinophil degranulation may also directly trigger neural excitation, muscle contractions and pain. In a subset of FD cases, both mast cells and eosinophils may be recruited, and both cell types are a key link between innate and adaptive immunities. It is possible that in other cases, the eosinophils are protective and reduce injury, promoting healing and symptom resolution. This hypothetical pathway needs rigorous testing in animal and human models of the disease.

\section{DIAGNOSIS}

Diagnosis of FD remains one of exclusion. Data from Asia shows that $40 \%$ to $80 \%$ of patients presenting with dyspepsia were diagnosed with FD after a complete workup $[65,66]$.

EGD can exclude esophagitis, peptic ulcer disease and esophagogastric cancers. The Asian consensus report recommends that all patients presenting with dyspepsia aged 40 years or over and in regions of high prevalence cancer should undergo EGD to exclude cancer [4]. Similarly, the consensus recommended EGD for all those presenting with alarming symptoms (e.g., weight loss, vomiting, dysphagia, bleeding, or a family history of cancer), although the positive predictive value of these alarming symptoms is low (i.e., most people presenting with one of these symptoms will not have cancer) [67].

Those with new onset dyspepsia who are young and 
have no alarming symptoms have the option to enter an empirical therapy trial, with a choice between testing and treating $\mathrm{H}$. pylori or empiric acid suppression, depending on the local prevalence of $\mathrm{H}$. pylori and gastric cancer, the health care treatment policy, and patient preference $[4,68]$. Unfortunately, endoscopy fails to provide reassurance to patients with FD, with no improvement in quality of life or psychological distress observed in a cohort both before and 1 month after endoscopy [69].

Differentiating GERD from FD is not straightforward, as esophageal and gastroduodenal symptoms often coexist. Many patients with GERD do not have esophagitis, but they may still have GERD (non-erosive reflux disease). In a Chinese study, pathologic acid reflux in the esophagus, as measured by ambulatory 24 -hour $\mathrm{pH}$ monitoring, was detected in over $25 \%$ of patients with FD and was most prevalent in those with epigastric burning [70]. The symptoms of GERD occur more commonly in FD than expected by chance in the West and Asia, suggesting a shared pathophysiology [71]. Recently, a close link between transient lower esophageal sphincter relaxations (TLESRs), which occur in GERD, and gastric accommodation was observed, and it has been suggested that activation of mechanoreceptors is involved in triggering the TLESRs [72]. If gastric accommodation and GERD are linked through TLESRs, it would not be surprising that those with gastric accommodation dysfunction experience more heartburn, potentially explaining the close relationship between GERD and FD [72].

FD also overlaps with IBS more than expected by chance, including in Asia, suggesting that FD is part of a spectrum of FGIDs with similar pathophysiology, and thus attempting to identify each by symptoms alone is problematic [25]. A working hypothesis is that if eosinophils and mast cells are recruited into the small intestine, both FD and IBS may result, while if mast cells alone infiltrate, then IBS but not FD will occur [7].

In view of the association of FD with duodenal eosinophilia in Western countries in the absence of obvious parasites, it is interesting that parasitic infestation may present more commonly with dyspepsia in Asia, including giardiasis, ascariasis, fascioliasis, and opisthorchiasis [73]. However randomized controlled trials establishing a causal relationship are lacking. Hepatocellular carcinoma is prevalent in Asia because of hepatitis B infection and may manifest initially with dyspepsia [68].

Chronic dyspepsia may result from gastroduodenal disease, but pancreaticobiliary disease should also be considered in the correct clinical setting [74]. Biliary pain can be epigastric but is usually more severe, episodic, and unpredictable and may radiate to the back or shoulder. Pancreatic pain may also be confused with EPS. Celiac disease may be confused with FD in some cases, although a true association remains to be confirmed [75]. Side effects from drugs (e.g., from NSAID ingestion) rarely causes chronic dyspepsia that is confused with FD [76]. Duodenal eosinophilia may be a useful diagnostic marker in the correct clinical setting, but its value in clinical practice remains to be confirmed [40].

\section{TREATMENT}

Once a firm diagnosis of FD has been established, it is clinically useful to subdivide FD into EPS or PDS when planning treatment (Table 1) [77]. All patients with FD should be reassured that FD is not associated with any increase in mortality [78]. Dietary change may help in some cases, including smaller regular meals and reduced fat intake (fat can slow gastric emptying) [32,33]. Reducing anxiety and addressing other psychological issues is often helpful, and formal psychological interventions should be considered in cases with resistant symptoms $[48,79,80]$.

\section{Testing for and treating $H$. pylori}

Although it has been controversial, it is reasonable to test for $H$. pylori in all FD cases and treat the infected cases [68]. Eradication therapy only helps a minority of cases (NNT, 17) [81], but as the benefits are long-term, the risk-to-benefit ratio is arguably favorable $[82,83]$. Further, eradication of the infection reduces the risk of future peptic ulcer disease (and missed peptic ulcers may explain a minority of cases with suspected FD, as the ulcer may have healed by the time endoscopy is undertaken), and eradication may reduce the risk of gastric cancer if atrophic gastritis has not supervened [68]. There is evidence that $H$. pylori may be more strongly linked to EPS, but this is controversial [84]. Admittedly, no eradication therapy trials have been conducted in $\mathrm{H}$. pylori-negative 
Table 1. Treatment options in functional dyspepsia

\begin{tabular}{|c|c|c|}
\hline Therapeutic intervention & Efficacy & Subgroup most likely to benefit \\
\hline Helicobacter pylori eradication & Superior to placebo & EPS \\
\hline Proton pump inhibitors & Superior to placebo & EPS \\
\hline H2-receptor antagonists & Superior to placebo & EPS \\
\hline Acotiamide & Superior to placebo & PDS \\
\hline Buspirone & Superior to placebo & PDS \\
\hline Antidepressants-TCAs & Superior to placebo if normal gastric emptying & EPS \\
\hline Antidepressants-SSRI, SNRI & No better than placebo & \\
\hline Antacids & No better than placebo & \\
\hline Bismuth salts & No better than placebo & \\
\hline Sucralfate & No better than placebo & \\
\hline
\end{tabular}

EPS, epigastric pain syndrome; PDS, postprandial distress syndrome; TCA, tricyclic antidepressant; SSRI, selective serotonin reuptake inhibitor; SNRI, selective norepinephrine reuptake inhibitor.

FD cases to confirm that the benefit is not related to any effects of other gut bacteria.

If an infection is found, offering eradication therapy and re-testing at least 1 month after therapy cessation to confirm that a cure is reasonable. Current first line eradication therapy fails to cure the infection in more than $30 \%$ of cases [85]. In those who are cured and remain so 12 months post-therapy, this arguably suggests they never had FD but rather suffered from $H$. pylori-induced organic dyspepsia [68], although this is more an argument of semantics.

\section{Epigastric pain syndrome: first line}

Acid suppression reduces FD symptoms compared with a placebo, and meta-analysis data suggest that EPS is most likely to respond [81]. Proton pump inhibitor (PPI) therapy and $\mathrm{H}_{2}$ receptor antagonist therapy are both superior to a placebo, with $\mathrm{H}_{2}$ blockers having a larger benefit, but the data are more heterogeneous [81].

Notably, while it is used most widely and recommended most often, only a minority of individuals respond to PPIs, and their long-term use can have adverse side effects [81]. Most studies are based on Western populations, but a randomized placebo-controlled trial from Hong Kong in young subjects with uninvestigated epigastric pain who were $H$. pylori-negative failed to demonstrate a benefit of PPI therapy [86], and similar results were reported overall for FD [87]. A Japanese trial showed that $15 \mathrm{mg}$ lansoprazole was superior to a placebo for FD, but only EPS responded to the drug [88].
Another trial from Japan failed to demonstrate any differences by subgroup, although FD responded to $20 \mathrm{mg}$ rebaprazole, but not to the other doses tested [89].

If a PPI fails after an adequate full-dose therapy trial, it is reasonable to try a $\mathrm{H}_{2}$ receptor antagonist. An alternative is to try a prokinetic, especially if the symptoms of EPS and PDS overlap [9o].

\section{Postprandial distress syndrome: first line}

A prokinetic is usually offered as a first line treatment, but options vary by country and remain restrictive. Very limited data support the use of domperidone, a dopamine antagonist, and the same applies to metoclopramide [77,91]. Cisapride, a serotonin type $4\left(5 \mathrm{HT}_{4}\right)$ agonist and serotonin type $3\left(5 \mathrm{HT}_{3}\right)$ antagonist, has been withdrawn in most countries because of QT prolongation, but it was superior to a placebo in cases with FD [81]. Tegaserod, a $5 \mathrm{HT}_{4}$ agonist, was marginally better than a placebo [90], while mosapride is probably not efficacious [92], and itopride is of uncertain benefit over a placebo [93].

Acotiamide is approved for FD in Japan. The drug relaxes the gastric fundus and accelerates gastric emptying in humans [94]. A modest but significant benefit over a placebo was observed in FD, with $52 \%$ of those on acotiamide for over 4 weeks responding, compared with $35 \%$ on the placebo, based on a global assessment of the overall treatment effect [95]. Complete loss of meal-related symptoms occurred in $15 \%$ of those on acotiamide versus $9 \%$ on a placebo, which was significant statisti- 
cally but arguable in terms of clinical efficacy [95]. Other drugs also relax the gastric fundus and may have a value in treating FD, including the anti-anxiety drug and serotonin type 1a agonist buspirone and tandospirone, and the anti-migraine drug and serotonin type 1 agonist, sumatriptan $[96,97]$, but data remain limited.

\section{Centrally acting therapy}

If first line therapy fails, a centrally acting drug may be considered. In the Functional Dyspepsia Treatment Trial conducted in North America, a low dose tricyclic antidepressant (amitryptiline $50 \mathrm{mg}$ ) was compared with a selective serotonin reuptake inhibitor (SSRI) in antidepressant dosing (escitalopram $10 \mathrm{mg}$ ) and a placebo over 3 months with a 6-month follow-up post-therapy [98]. The SSRI performed no better than the placebo, which was consistent with other clinical data on a selective serotonin norepinephrine reuptake inhibitor (SNRI), venlafaxine [99]. On the other hand, the tricyclic antidepressant appeared to provide a modest benefit for FD, especially in those with pain [98]. Patients with ulcer-like FD, likely equivalent to EPS, who were given amitriptyline were over 3 -fold more likely to report adequate relief than were those who received the placebo, although the patient diaries showed that meal-related symptoms also benefited compared with the placebo. Interestingly, tricyclics can theoretically slow gastric emptying, and those with delayed gastric emptying were less likely to report adequate relief on amitriptyline compared with FD patients with normal emptying. Notably, antidepressant therapy did not change psychological distress measures, and did not alter gastric emptying rates.

Another promising approach is the use of the teracyclic antidepressant mirtazepine. Although mirtazepine does not alter gastric function [100], results from a preliminary randomized controlled trial of FD suggest benefits over a placebo [101]. Levosulpiride is an atypical anti-psychotic drug that is a benzamide derivate and dopamine [2] antagonist; in cases with FD, it may be as efficacious as cisapride, but more data are needed, including large placebo controlled trials [102].

Psychological therapies are of uncertain benefit in FD, although positive trial data have been reported [103]. However, combining medical therapies with psychological therapy may provide better outcomes, although large-scale trials are needed to confirm these observa- tions [79,104].

\section{Anti-inflammatory therapy}

Little data exist on the use of anti-eosinophil therapies in FD. Anecdotally, anti-histamine therapy has helped some patients with FD. In children, eosinophil stabilization using montelukast did not reduce eosinophil numbers but did reduce symptoms [105].

\section{Alternative therapy}

Herbal products have been tested for their effectiveness in FD, with variable and often negative results [106]. The combination herbal product iberogast (STW-5, Medical Futures Inc., Richmond Hill, ON, Canada) relaxes the gastric fundus [106] and was superior to a placebo in a randomized controlled trial, although the quality of the randomized trial data were low $[107,108]$.

Rikkunshito is a Japanese herbal medicine that increases acyl ghrelin levels and may improve FD symptoms, although this appears to be restricted to $H$. pylori-infected individuals and requires confirmation [109]. Overall, convincing data supporting the use of any herbal therapies for treatment of FD are lacking. An intriguing approach is to pass an electric current through the abdomen, which in one small randomized controlled trial, appeared to reduce the symptoms of pain and meal-related complaints, but the findings need to be confirmed [110].

\section{CONCLUSIONS}

FD is a common disorder affecting every one in 10 of the general population. Management relies on an accurate diagnosis, including ruling out less common causes of similar symptoms, followed by reassurance and approaches to reduce stress and modify any dietary triggers. Once FD is confirmed, $H$. pylori can be identified reasonably and infected cases treated, although only a minority will have true $H$. pylori-induced dyspepsia and respond to treatment. In those with EPS, acid suppression therapy is a first line therapy, but a $\mathrm{H}_{2}$ blocker is worth a trial even if PPI fails. In PDS, a prokinetic is preferred, but switching between these drug classes should be considered if the therapy fails. A second line therapy includes administration of a tricyclic antidepressant in 
low doses, or mirtazapine, but not an SSRI or SNRI.

\section{Conflict of interest}

NJT has research support from GI Therapies, Janssen, Prometheus, Pfizer and Salix, and has consulted for Adelphi Values, Allergens, GI Therapies and Yuhan.

\section{REFERENCES}

1. Camilleri M, Dubois D, Coulie B, et al. Prevalence and socioeconomic impact of upper gastrointestinal disorders in the United States: results of the US Upper Gastrointestinal Study. Clin Gastroenterol Hepatol 2005;3:543-552.

2. Lacy BE, Weiser KT, Kennedy AT, Crowell MD, Talley NJ. Functional dyspepsia: the economic impact to patients. Aliment Pharmacol Ther 2013;38:170-177.

3. Tack J, Talley NJ. Functional dyspepsia: symptoms, definitions and validity of the Rome III criteria. Nat Rev Gastroenterol Hepatol 2013;10:134-141.

4. Miwa H, Ghoshal UC, Gonlachanvit S, et al. Asian consensus report on functional dyspepsia. J Neurogastroenterol Motil 2012;18:150-168.

5. Futagami S, Itoh T, Sakamoto C. Systematic review with meta-analysis: post-infectious functional dyspepsia. Aliment Pharmacol Ther 2015;41:177-188.

6. Walker MM, Aggarwal KR, Shim LS, et al. Duodenal eosinophilia and early satiety in functional dyspepsia: confirmation of a positive association in an Australian cohort. J Gastroenterol Hepatol 2014;29:474-9.

7. Walker MM, Talley NJ, Prabhakar M, et al. Duodenal mastocytosis, eosinophilia and intraepithelial lymphocytosis as possible disease markers in the irritable bowel syndrome and functional dyspepsia. Aliment Pharmacol Ther 2009;29:765-773.

8. Liebregts T, Adam B, Bredack C, et al. Small bowel homing $\mathrm{T}$ cells are associated with symptoms and delayed gastric emptying in functional dyspepsia. Am J Gastroenterol 2011;106:1089-1098.

9. Tack J, Talley NJ, Camilleri M, et al. Functional gastroduodenal disorders. Gastroenterology 2006;130:1466-1479.

10. Jiang X, Locke GR 3rd, Choung RS, Zinsmeister AR, Schleck CD, Talley NJ. Prevalence and risk factors for abdominal bloating and visible distention: a population-based study. Gut 2008;57:756-763.

11. Choung RS, Locke GR, Schleck CD, Zinsmeister AR, Tall- ey NJ. Do distinct dyspepsia subgroups exist in the community? A population-based study. Am J Gastroenterol 2007;102:1983-1989.

12. Ford AC, Bercik P, Morgan DG, Bolino C, Pintos-Sanchez MI, Moayyedi P. The Rome III criteria for the diagnosis of functional dyspepsia in secondary care are not superior to previous definitions. Gastroenterology 2014;146:932940.

13. Aro P, Talley NJ, Agreus L, et al. Functional dyspepsia impairs quality of life in the adult population. Aliment Pharmacol Ther 2011;33:1215-1224.

14. Aro P, Talley NJ, Ronkainen J, et al. Anxiety is associated with uninvestigated and functional dyspepsia (Rome III criteria) in a Swedish population-based study. Gastroenterology 2009;137:94-100.

15. Zagari RM, Law GR, Fuccio L, et al. Epidemiology of functional dyspepsia and subgroups in the Italian general population: an endoscopic study. Gastroenterology 2010;138:1302-1311.

16. Ghoshal UC, Singh R, Chang FY, et al. Epidemiology of uninvestigated and functional dyspepsia in Asia: facts and fiction. J Neurogastroenterol Motil 2011;17:235-244.

17. Lee H, Jung HK, Huh KC; Functional Dyspepsia Study Group in the Korean Society of Neurogastroenterology and Motility. Current status of functional dyspepsia in Korea. Korean J Intern Med 2014;29:156-165.

18. Min BH, Huh KC, Jung HK, et al. Prevalence of uninvestigated dyspepsia and gastroesophageal reflux disease in Korea: a population-based study using the Rome III criteria. Dig Dis Sci 2014;59:2721-2729.

19. van Kerkhoven LA, Laheij RJ, Meineche-Schmidt V, Veldhuyzen-van Zanten SJ, de Wit NJ, Jansen JB. Functional dyspepsia: not all roads seem to lead to rome. J Clin Gastroenterol 2009;43:118-122.

20. Fang YJ, Liou JM, Chen CC, et al. Distinct aetiopathogenesis in subgroups of functional dyspepsia according to the Rome III criteria. Gut 2015;64:1517-1528.

21. Lan L, Yu J, Chen YL, et al. Symptom-based tendencies of Helicobacter pylori eradication in patients with functional dyspepsia. World J Gastroenterol 2011;17:3242-3247.

22. Walker MM, Talley NJ. Review article: bacteria and pathogenesis of disease in the upper gastrointestinal tract: beyond the era of Helicobacter pylori. Aliment Pharmacol Ther 2014;39:767-779.

23. Fikree A, Aktar R, Grahame R, et al. Functional gastrointestinal disorders are associated with the joint hypermo- 
bility syndrome in secondary care: a case-control study. Neurogastroenterol Motil 2015;27:569-579.

24. Ford AC, Talley NJ, Walker MM, Jones MP. Increased prevalence of autoimmune diseases in functional gastrointestinal disorders: case-control study of 23471 primary care patients. Aliment Pharmacol Ther 2014;40:827-834.

25. $\mathrm{Hu}$ WH, Wong WM, Lam CL, et al. Anxiety but not depression determines health care-seeking behaviour in Chinese patients with dyspepsia and irritable bowel syndrome: a population-based study. Aliment Pharmacol Ther 2002;16:2081-2088.

26. Pajala M, Heikkinen M, Hintikka J. Association between mental distress, gastrointestinal symptoms, and healthcare utilization in functional dyspepsia: a prospective 7-year follow-up study. Scand J Gastroenterol 2012;47:407413.

27. Koloski NA, Talley NJ, Huskic SS, Boyce PM. Predictors of conventional and alternative health care seeking for irritable bowel syndrome and functional dyspepsia. Aliment Pharmacol Ther 2003;17:841-851.

28. Ahlawat SK, Richard Locke G, Weaver AL, Farmer SA, Yawn BP, Talley NJ. Dyspepsia consulters and patterns of management: a population-based study. Aliment Pharmacol Ther 2005;22:251-259.

29. Koloski NA, Boyce PM, Talley NJ. Is health care seeking for irritable bowel syndrome and functional dyspepsia a socially learned response to illness? Dig Dis Sci 2005:50:153-162.

30. Bisschops R, Karamanolis G, Arts J, et al. Relationship between symptoms and ingestion of a meal in functional dyspepsia. Gut 2008;57:1495-1503.

31. Pilichiewicz AN, Horowitz M, Holtmann GJ, Talley NJ, Feinle-Bisset C. Relationship between symptoms and dietary patterns in patients with functional dyspepsia. Clin Gastroenterol Hepatol 2009;7:317-322.

32. Keshteli AH, Feizi A, Esmaillzadeh A, et al. Patterns of dietary behaviours identified by latent class analysis are associated with chronic uninvestigated dyspepsia. Br J Nutr 2015;113:803-812.

33. Pilichiewicz AN, Feltrin KL, Horowitz M, et al. Functional dyspepsia is associated with a greater symptomatic response to fat but not carbohydrate, increased fasting and postprandial CCK, and diminished PYY. Am J Gastroenterol 2008;103:2613-2623.

34. Kazemi M, Eshraghian A, Hamidpour L, Taghavi S. Changes in serum ghrelin level in relation to meal-time in patients with functional dyspepsia. United European Gastroenterol J 2015;3:11-16.

35. Rhee PL, Kim YH, Son HJ, et al. The etiologic role of gastric hypersensitivity in functional dyspepsia in Korea. J Clin Gastroenterol 1999;29:332-335.

36. Jones MP, Talley NJ, Eslick GD, Dubois D, Tack J. Community subgroups in dyspepsia and their association with weight loss. Am J Gastroenterol 2008;103:2051-2060.

37. Le Pluart D, Sabate JM, Bouchoucha M, Hercberg S, Benamouzig R, Julia C. Functional gastrointestinal disorders in 35,447 adults and their association with body mass index. Aliment Pharmacol Ther 2015;41:758-767.

38. Lee KJ, Tack J. Duodenal implications in the pathophysiology of functional dyspepsia. J Neurogastroenterol Motil 2010;16:251-257.

39. Talley NJ, Walker MM, Aro P, et al. Non-ulcer dyspepsia and duodenal eosinophilia: an adult endoscopic population-based case-control study. Clin Gastroenterol Hepatol 2007;5:1175-1183.

40. Walker MM, Salehian SS, Murray CE, et al. Implications of eosinophilia in the normal duodenal biopsy: an association with allergy and functional dyspepsia. Aliment Pharmacol Ther 2010;31:1229-1236.

41. Wang X, Li X, Ge W, et al. Quantitative evaluation of duodenal eosinophils and mast cells in adult patients with functional dyspepsia. Ann Diagn Pathol 2015;19:50-56.

42. Futagami S, Shindo T, Kawagoe T, et al. Migration of eosinophils and CCR2-/CD68-double positive cells into the duodenal mucosa of patients with postinfectious functional dyspepsia. Am J Gastroenterol 2010;105:1835-1842.

43. Vanheel H, Vicario M, Vanuytsel T, et al. Impaired duodenal mucosal integrity and low-grade inflammation in functional dyspepsia. Gut 2014;63:262-271.

44. Jones MP, Walker MM, Ford AC, Talley NJ. The overlap of atopy and functional gastrointestinal disorders among 23,471 patients in primary care. Aliment Pharmacol Ther 2014;40:382-391.

45. Mazzoleni LE, Sander GB, Francesconi CF, et al. Helicobacter pylori eradication in functional dyspepsia: HEROES trial. Arch Intern Med 2011;171:1929-1936.

46. Moayyedi P, Deeks J, Talley NJ, Delaney B, Forman D. An update of the Cochrane systematic review of Helicobacter pylori eradication therapy in nonulcer dyspepsia: resolving the discrepancy between systematic reviews. Am J Gastroenterol 2003;98:2621-2626.

47. Jones MP, Oudenhove LV, Koloski N, Tack J, Talley NJ. 
Early life factors initiate a 'vicious circle' of affective and gastrointestinal symptoms: a longitudinal study. United European Gastroenterol J 2013;1:394-402.

48. Aro P, Talley NJ, Johansson SE, Agreus L, Ronkainen J. Anxiety is linked to new-onset dyspepsia in the Swedish population: a 10-year follow-up study. Gastroenterology 2015;148:928-937.

49. Liebregts T, Adam B, Bredack C, et al. Immune activation in patients with irritable bowel syndrome. Gastroenterology 2007;132:913-920.

50. Mayer EA, Gupta A, Kilpatrick LA, Hong JY. Imaging brain mechanisms in chronic visceral pain. Pain 2015;156 Suppl 1:S50-S63.

51. Zeng F, Qin W, Liang F, et al. Abnormal resting brain activity in patients with functional dyspepsia is related to symptom severity. Gastroenterology 2011;141:499-506.

52. Nan J, Liu J, Mu J, et al. Brain-based correlations between psychological factors and functional dyspepsia. J Neurogastroenterol Motil 2015;21:103-110.

53. Nan J, Liu J, Mu J, et al. Anatomically related gray and white matter alterations in the brains of functional dyspepsia patients. Neurogastroenterol Motil 2015;27:856864.

54. Ly HG, Ceccarini J, Weltens N, et al. Increased cerebral cannabinoid-1 receptor availability is a stable feature of functional dyspepsia: a [F]MK-9470 PET study. Psychother Psychosom 2015;84:149-158.

55. Sarnelli G, D'Alessandro A, Pesce M, Palumbo I, Cuomo R. Genetic contribution to motility disorders of the upper gastrointestinal tract. World J Gastrointest Pathophysiol 2013;4:65-73.

56. Holtmann G, Siffert W, Haag S, et al. G-protein beta 3 subunit $825 \mathrm{CC}$ genotype is associated with unexplained (functional) dyspepsia. Gastroenterology 2004;126:971-979.

57. Park JM, Baeg MK, Lim CH, Cho YK, Choi MG. Nitric oxide synthase gene polymorphisms in functional dyspepsia. Dig Dis Sci 2014;59:72-77.

58. Tahara T, Shibata T, Nakamura M, et al. Homozygous TRPV1 $315 \mathrm{C}$ influences the susceptibility to functional dyspepsia. J Clin Gastroenterol 2010;44:e1-e7.

59. Arisawa T, Tahara T, Shiroeda H, et al. Genetic polymorphisms of SCN1oA are associated with functional dyspepsia in Japanese subjects. J Gastroenterol 2013;48:73-80.

6o. Arisawa T, Tahara T, Shibata T, et al. Genetic polymorphisms of cyclooxygenase-1 (COX-1) are associated with functional dyspepsia in Japanese women. J Womens
Health (Larchmt) 2008;17:1039-1043.

61. Holtmann G, Talley NJ. Hypothesis driven research and molecular mechanisms in functional dyspepsia: the beginning of a beautiful friendship in research and practice? Am J Gastroenterol 2006;101:593-595.

62. Powell N, Walker MM, Talley NJ. Gastrointestinal eosinophils in health, disease and functional disorders. Nat Rev Gastroenterol Hepatol 2010;7:146-156.

63. Walker MM, Powell N, Talley NJ. Atopy and the gastrointestinal tract: a review of a common association in unexplained gastrointestinal disease. Expert Rev Gastroenterol Hepatol 2014;8:289-299.

64. Walker MM, Warwick A, Ung C, Talley NJ. The role of eosinophils and mast cells in intestinal functional disease. Curr Gastroenterol Rep 2011;13:323-330.

65. Kwan AC, Bao T, Chakkaphak S, et al. Validation of Rome II criteria for functional gastrointestinal disorders by factor analysis of symptoms in Asian patient sample. J Gastroenterol Hepatol 2003;18:796-802.

66. Wai CT, Yeoh KG, Ho KY, Kang JY, Lim SG. Diagnostic yield of upper endoscopy in Asian patients presenting with dyspepsia. Gastrointest Endosc 2002;56:548-551.

67. Hammer J, Eslick GD, Howell SC, Altiparmak E, Talley NJ. Diagnostic yield of alarm features in irritable bowel syndrome and functional dyspepsia. Gut 2004;53:666-672.

68. Miwa H, Kusano M, Arisawa T, et al. Evidence-based clinical practice guidelines for functional dyspepsia. J Gastroenterol 2015;50:125-139.

69. van Kerkhoven LA, van Rossum LG, van Oijen MG, Tan AC, Laheij RJ, Jansen JB. Upper gastrointestinal endoscopy does not reassure patients with functional dyspepsia. Endoscopy 2006;38:879-885.

70. Xiao YL, Peng S, Tao J, et al. Prevalence and symptom pattern of pathologic esophageal acid reflux in patients with functional dyspepsia based on the Rome III criteria. Am J Gastroenterol 2010;105:2626-2631.

71. Lee SY, Lee KJ, Kim SJ, Cho SW. Prevalence and risk factors for overlaps between gastroesophageal reflux disease, dyspepsia, and irritable bowel syndrome: a population-based study. Digestion 2009;79:196-201.

72. Pauwels A, Altan E, Tack J. The gastric accommodation response to meal intake determines the occurrence of transient lower esophageal sphincter relaxations and reflux events in patients with gastro-esophageal reflux disease. Neurogastroenterol Motil 2014;26:581-588.

73. Kakati B, Dang S, Heif M, Caradine K, McKnight W, Aduli 
F. Strongyloides duodenitis: case report and review of literature. J Natl Med Assoc 2011;103:60-63.

74. Brawman-Mintzer O, Durkalski V, Wu Q, et al. Psychosocial characteristics and pain burden of patients with suspected sphincter of Oddi dysfunction in the EPISOD multicenter trial. Am J Gastroenterol 2014;109:436-442.

75. Zanini B, Lanzarotto F, Villanacci V, Carabellese N, Ricci C, Lanzini A. Clinical expression of lymphocytic duodenosis in "mild enteropathy" celiac disease and in functional gastrointestinal syndromes. Scand J Gastroenterol 2014;49:794-800.

76. Bytzer P, Hallas J. Drug-induced symptoms of functional dyspepsia and nausea: a symmetry analysis of one million prescriptions. Aliment Pharmacol Ther 2000;14:1479-1484.

77. Zala AV, Walker MM, Talley NJ. Emerging drugs for functional dyspepsia. Expert Opin Emerg Drugs 2015;20:221233.

78. Chang JY, Locke GR 3rd, McNally MA, et al. Impact of functional gastrointestinal disorders on survival in the community. Am J Gastroenterol 2010;105:822-832.

79. Orive M, Barrio I, Orive VM, et al. A randomized controlled trial of a 10 week group psychotherapeutic treatment added to standard medical treatment in patients with functional dyspepsia. J Psychosom Res 2015;78:563568.

8o. Faramarzi M, Azadfallah P, Book HE, Tabatabaei KR, Taheri H, Shokri-shirvani J. A randomized controlled trial of brief psychoanalytic psychotherapy in patients with functional dyspepsia. Asian J Psychiatr 2013;6:228-234.

81. Talley NJ; American Gastroenterological Association. American Gastroenterological Association medical position statement: evaluation of dyspepsia. Gastroenterology 2005;129:1753-1755.

82. Zhao B, Zhao J, Cheng WF, et al. Efficacy of Helicobacter pylori eradication therapy on functional dyspepsia: a meta-analysis of randomized controlled studies with 12-month follow-up. J Clin Gastroenterol 2014;48:241-247.

83. Zullo A, Hassan C, De Francesco V, et al. Helicobacter pylori and functional dyspepsia: an unsolved issue? World J Gastroenterol 2014;20:8957-8963.

84. Xu S, Wan X, Zheng X, et al. Symptom improvement after helicobacter pylori eradication in patients with functional dyspepsia: a multicenter, randomized, prospective cohort study. Int J Clin Exp Med 2013;6:747-756.

85. Malfertheiner P, Megraud F, O'Morain CA, et al. Management of Helicobacter pylori infection: the Maastricht IV/
Florence Consensus Report. Gut 2012;61:646-664.

86. Leung WK, Wu JC, Chan FK, et al. Initial treatment with lansoprazole in young dyspeptic patients with negative urea breath test result: a randomized controlled trial with 12-month follow-up. Am J Gastroenterol 2007;102:14831488.

87. Wong WM, Wong BC, Hung WK, et al. Double blind, randomised, placebo controlled study of four weeks of lansoprazole for the treatment of functional dyspepsia in Chinese patients. Gut 2002;51:502-506.

88. Suzuki H, Kusunoki H, Kamiya T, et al. Effect of lansoprazole on the epigastric symptoms of functional dyspepsia (ELF study): a multicentre, prospective, randomized, double-blind, placebo-controlled clinical trial. United European Gastroenterol J 2013;1:445-452.

89. Iwakiri R, Tominaga K, Furuta K, et al. Randomised clinical trial: rabeprazole improves symptoms in patients with functional dyspepsia in Japan. Aliment Pharmacol Ther 2013;38:729-740.

90. Lacy BE, Talley NJ, Locke GR 3rd, et al. Review article: current treatment options and management of functional dyspepsia. Aliment Pharmacol Ther 2012;36:3-15.

91. Acosta A, Camilleri M. Prokinetics in gastroparesis. Gastroenterol Clin North Am 2015;44:97-111.

92. Bang CS, Kim JH, Baik GH, et al. Mosapride treatment for functional dyspepsia: a meta-analysis. J Gastroenterol Hepatol 2015;30:28-42.

93. Huang X, Lv B, Zhang S, Fan YH, Meng LN. Itopride therapy for functional dyspepsia: a meta-analysis. World J Gastroenterol 2012;18:7371-7377.

94. Kusunoki H, Haruma K, Manabe N, et al. Therapeutic efficacy of acotiamide in patients with functional dyspepsia based on enhanced postprandial gastric accommodation and emptying: randomized controlled study evaluation by real-time ultrasonography. Neurogastroenterol Motil 2012;24:540-545, e250-e251.

95. Matsueda K, Hongo M, Tack J, Saito Y, Kato H. A placebo-controlled trial of acotiamide for meal-related symptoms of functional dyspepsia. Gut 2012;61:821-828.

96. Tack J, Janssen P, Masaoka T, Farre R, Van Oudenhove L. Efficacy of buspirone, a fundus-relaxing drug, in patients with functional dyspepsia. Clin Gastroenterol Hepatol 2012;10:1239-1245.

97. Miwa H, Nagahara A, Tominaga K, et al. Efficacy of the 5-HT1A agonist tandospirone citrate in improving symptoms of patients with functional dyspepsia: a randomized 
controlled trial. Am J Gastroenterol 2009;104:2779-2787.

98. Talley NJ, Locke GR, Saito YA, et al. Effect of amitriptyline and escitalopram on functional dyspepsia: a multicenter, randomized controlled study. Gastroenterology 2015;149:340-349.

99. van Kerkhoven LA, Laheij RJ, Aparicio N, et al. Effect of the antidepressant venlafaxine in functional dyspepsia: a randomized, double-blind, placebo-controlled trial. Clin Gastroenterol Hepatol 2008;6:746-752.

100. Choung RS, Cremonini F, Thapa P, Zinsmeister AR, Talley NJ. The effect of short-term, low-dose tricyclic and tetracyclic antidepressant treatment on satiation, postnutrient load gastrointestinal symptoms and gastric emptying: a double-blind, randomized, placebo-controlled trial. Neurogastroenterol Motil 2008;20:220-227.

101. Vanheel H, Tack J. Therapeutic options for functional dyspepsia. Dig Dis 2014;32:230-234.

102. Mearin F, Rodrigo L, Perez-Mota A, et al. Levosulpiride and cisapride in the treatment of dysmotility-like functional dyspepsia: a randomized, double-masked trial. Clin Gastroenterol Hepatol 2004;2:301-308.

103. Calvert EL, Houghton LA, Cooper P, Morris J, Whorwell PJ. Long-term improvement in functional dyspepsia using hypnotherapy. Gastroenterology 2002;123:1778-1785.

104. Haag S, Senf W, Tagay S, et al. Is there a benefit from intensified medical and psychological interventions in patients with functional dyspepsia not responding to con- ventional therapy? Aliment Pharmacol Ther 2007;25:973986.

105. Friesen CA, Schurman JV, Colombo JM, Abdel-Rahman SM. Eosinophils and mast cells as therapeutic targets in pediatric functional dyspepsia. World J Gastrointest Pharmacol Ther 2013;4:86-96.

106. Holtmann G, Talley NJ. Herbal medicines for the treatment of functional and inflammatory bowel disorders. Clin Gastroenterol Hepatol 2015;13:422-432.

107. Pilichiewicz AN, Horowitz M, Russo A, et al. Effects of Iberogast on proximal gastric volume, antropyloroduodenal motility and gastric emptying in healthy men. Am J Gastroenterol 2007;102:1276-1283.

108. Rosch W, Liebregts T, Gundermann KJ, Vinson B, Holtmann G. Phytotherapy for functional dyspepsia: a review of the clinical evidence for the herbal preparation STW 5 . Phytomedicine 2006;13 Suppl 5:114-121.

109. Suzuki H, Matsuzaki J, Fukushima Y, et al. Randomized clinical trial: rikkunshito in the treatment of functional dyspepsia. A multicenter, double-blind, randomized, placebo-controlled study. Neurogastroenterol Motil 2014;26:950-961.

110. Koklu S, Koklu G, Ozguclu E, Kayani GU, Akbal E, Hascelik Z. Clinical trial: interferential electric stimulation in functional dyspepsia patients. A prospective randomized study. Aliment Pharmacol Ther 2010;31:961-968. 